\title{
Chapter 13 \\ The Best Way to Reduce Discards Is by Not Catching Them!
}

\author{
David G. Reid, Julia Calderwood, Pedro Afonso, Pierre Bourdaud, \\ Laurence Fauconnet, José Manuel González-Irusta, Lars O. Mortensen, \\ Francesc Ordines, Sigrid Lehuta, Lionel Pawlowski, \\ Kristian S. Plet-Hansen, Zachary Radford, Marianne Robert, \\ Marie-Joelle Rochet, Lucía Rueda, Clara Ulrich, and Youen Vermard
}

\begin{abstract}
Under the Landing Obligation (LO) fishers will need to reduce or land fish that were previously discarded. In this chapter we look at how they might be able to do that by summarising a number of studies conducted in various European regions. We start by describing a series of "challenge" trials where fishers tried to reduce their discards by whatever (legal) means they thought best. In some cases, they were able to reduce unwanted catches, in others they were less successful. We also interviewed fishers not involved in the trials to ask them what they thought they could do. We explore their approaches which generally fell into three categories:
\end{abstract}

D. G. Reid $(\bowtie) \cdot$ J. Calderwood

Marine Institute, Oranmore, County Galway, Ireland

e-mail: David.Reid@Marine.ie

P. Afonso $\cdot$ L. Fauconnet $\cdot$ J. M. González-Irusta

Instituto do Mar (IMAR), Department of Oceanography and Fisheries, Marine and

Environmental Sciences Centre (MARE), and OKEANOS Research Unit, Universidade dos

Açores, Horta, Portugal

P. Bourdaud $\cdot$ S. Lehuta $\cdot$ Y. Vermard

Ifremer, Fisheries Ecol \& Modelling Unit, Nantes, France

L. O. Mortensen · K. S. Plet-Hansen · C. Ulrich

National Institute of Aquatic Resources, DTU Aqua, Technical University of Denmark, Kgs.

Lyngby, Denmark

F. Ordines $\cdot$ L. Rueda

Centro Oceanográfico de Baleares, Instituto Español de Oceanografía, Palma, Spain

L. Pawlowski · M. Robert

Fishery Technology and Biology Laboratory, IFREMER, Lorient, France

Z. Radford

Centre for Environment, Fisheries \& Aquaculture Science (Cefas), Lowestoft, UK

M.-J. Rochet

IFREMER, Centre Atlantique, Nantes, France

(C) The Author(s) 2019

S. S. Uhlmann et al. (eds.), The European Landing Obligation,

https://doi.org/10.1007/978-3-030-03308-8_13 
more selective gear; tactical and strategic changes; and management changes. Scientific data (surveys, landings, and observers data) can also be valuable to help fishers to decide where and when to fish to best avoid unwanted catches and maximise opportunities to catch their quotas. We provide some examples of this type of approach, and also how these can be adapted for use as interactive online apps that fishers can use in planning or whilst at sea.

Keywords Challenge trials $\cdot$ Decision support tools $\cdot$ Discard avoidance $\cdot$ Fine scale mapping $\cdot$ Fish distribution $\cdot$ Fishers $\cdot$ Fishing strategies $\cdot$ Hot-spot maps

\subsection{Introduction}

Under the Landing Obligation (LO) fishers will need to reduce or land fish that were previously discarded. In this context, understanding how fisheries operate is central to understand how to manage them (Hilborn 2007; Eliasen et al. 2014). An obvious way by which fishers can reduce discards is via improved gear selectivity (O'Neill et al., this volume). Beyond that, the tactical choices made by fishers on "where, when and how to fish" can play a central role in reducing discards (Rijnsdorp et al. 2012; Dunn et al. 2011). This can be implemented in terms of top down control (e.g. closed areas). However, the need for management to provide bottom-up incentives to reduce discards is also well established (Rochet et al. 2014; Condie et al. 2014; Little et al. 2015; Pascoe et al. 2010).

In parallel, the ongoing improvements in data availability open for new and more precise knowledge. Analysis of discard observers' information (e.g. Anon 2011; Viana et al. 2011) provides a better understanding of spatio-temporal patterns of discarding. Catch locations and landings per unit of effort can be determined at fine spatial scales from Vessel Monitoring Systems (VMS) and logbook data (e.g. Gerritsen and Lordan 2011), and increasingly from Electronic Monitoring (EM) data (Plet-Hansen et al. 2017). Bottom trawl surveys can be used to map the locations of species (Fraser et al. 2008), spawning aggregations (Nash et al. 2012) and size structure (Shephard et al. 2011). This information can help fishers to decide where and when to fish to avoid having to catch unwanted fish.

In this chapter we look at how fishers themselves may be able to change the way they operate in order to reduce discards, based on a series of recent studies performed in several European fisheries in the frame of the EU research project DiscardLess (www.discardless.eu). We start by describing a series of 'challenge' trials where several individual fishers tried to reduce their discards by whatever (legal) means they thought best. We also interviewed other fishers not involved in the trials to ask them what they thought they could do. Their approaches generally fell into three categories: more selective gear; tactical and strategic changes; and management changes (Reid 2017). After a description of the trials and their results, we look at other tools to help fishers decide where and when to fish to best avoid unwanted 
catches, and maximise their opportunities to catch their quotas. At the time of writing this summary, a number of the individual studies presented here were still ongoing and/or unpublished, but a more detailed description of the methods used and preliminary results has been reported in Reid and Fauconnet (2018).

Management changes are beyond the scope of this chapter but are addressed in other chapters of this book.

\subsection{What Can Fishers Themselves Do to Reduce Their Discards?}

In a series of "challenge experiments", individual vessels and crew were challenged to reduce their discards by whatever legal means available. Intuitively, this could be by (for example) changing the fishing gear, or by changing their fishing tactics, perhaps by shifting areas or seasons. Each vessel fished first with their normal approach (control) and then with the modified approach (test) with the aim of minimising discards over a predetermined period (challenge trial). They reported the adjustments they made and why. Skippers were asked to set themselves a target for discard reduction between the test and the control trips, and this was the core of the "challenge". The targets could have been in terms of reducing discards of TAC species in general, or of those that represent the major 'choke' species in their fishery, i.e. the species for which the available quota is exhausted (long) before the quotas are exhausted of (some of) the other species that are caught together in a (mixed) fishery (Zimmermann et al. 2015). Scientists were sometimes placed on-board to collect catch data, and also to train crews in self-sampling. The catch data were then analysed by scientists to determine the degree of success at reaching these targets.

Challenge trials were done in three different countries and across a number of fisheries. The approach was slightly different in the three countries:

- Ireland - one demersal trawl vessel targeting whitefish (cod, haddock and whiting) and one targeting Norway lobster (Nephrops norvegicus) with additional catches of the same fish species (Calderwood et al. 2016).

- Denmark - 12 demersal trawl vessels mainly fishing cod and saithe, with three vessels targeting Norway lobster. The vessels towed a mix of single and twin trawl rigs, and were distributed between the North Sea, the Skagerrak, and the Baltic Sea. (Mortensen et al. 2017).

- France - three vessels targeting a mix of species including cod, whiting, squid, cuttlefish and some pelagic species. The vessels were all demersal trawlers, two $<18 \mathrm{~m}$, and one $>18 \mathrm{~m}$ in length (Balazuc et al. 2016).

In Denmark, the main option explored by fishers was gear modification, and the data were mostly collected by the fishers themselves, supplemented with Fully Documented Fishery (FDF) methods (including Electronic Monitoring (EM) with 
cameras). In Ireland and France, the approaches included both gear and tactical modifications, with full observer coverage.

\subsubsection{Gear Based Changes Used in the "Challenge Trials"}

Changes to the fishing gear figured strongly in fisher's choices in all challenge trials. This was the main thrust of the Danish study, where the fishers used a variety of different gear modifications. These included:

- Changing mesh size in the codend of the net, usually to a larger mesh size, but in the Baltic Sea some vessels trialled reduced mesh sizes

- Inserting escape panels or separator panels into the net (with two codends for fish going above or below the panel)

- Topless trawl or modified mesh in an escape panel

In the French trials gear changes consisted of:

- The inclusion of a larger mesh cylinder in the extension (CMC)

- Separator panels with two codends

- Increased mesh size in the codend and extension, and T90 mesh

The only gear change in the Irish example was that one of the Irish vessels (the Nephrops targeting vessel) used a quad rig Nephrops net, with large mesh square mesh panels (SMP) in all four extensions.

The outcomes of these trials were somewhat mixed. In the Danish trials, nine vessels were able to reduce the discard ratio (Discards/Discards + Landings by species by weight) using the tested modifications (three in the North Sea, three in Skagerrak and three in the Baltic Sea), while two vessels (from the North Sea) actually increased their discard ratio and one North Sea vessel showed no difference. The improvements ranged from less than $2 \%$ for four of the vessels, $2-7 \%$ for four others, and, in one case, a $17.6 \%$ improvement (Fig. 13.1).

In the French trials, there was insufficient time after making the gear changes to collect sufficient data to analyse their performance. However, the vessel using the mesh cylinder (CMC) approach reported little loss of commercial catch volume, and in some cases reductions in discard volume. The separator panel with two codends could not be evaluated, but the skipper was still very positive and felt it had value. In general, the fishers did not feel that the changes in codend meshes achieved the results they had hoped for small fish, and there were concomitant losses in commercial sized fish (Balazuc et al. 2016).

In the Irish trials the use of the SMP in the quad rig allowed the vessel to keep fishing significantly longer before choking on the cod that was the main choke species during the control phase of the study. The results are shown in Fig. 13.2, and the reduction in over quota cod is clear, although there was an increase in over quota Nephrops. 

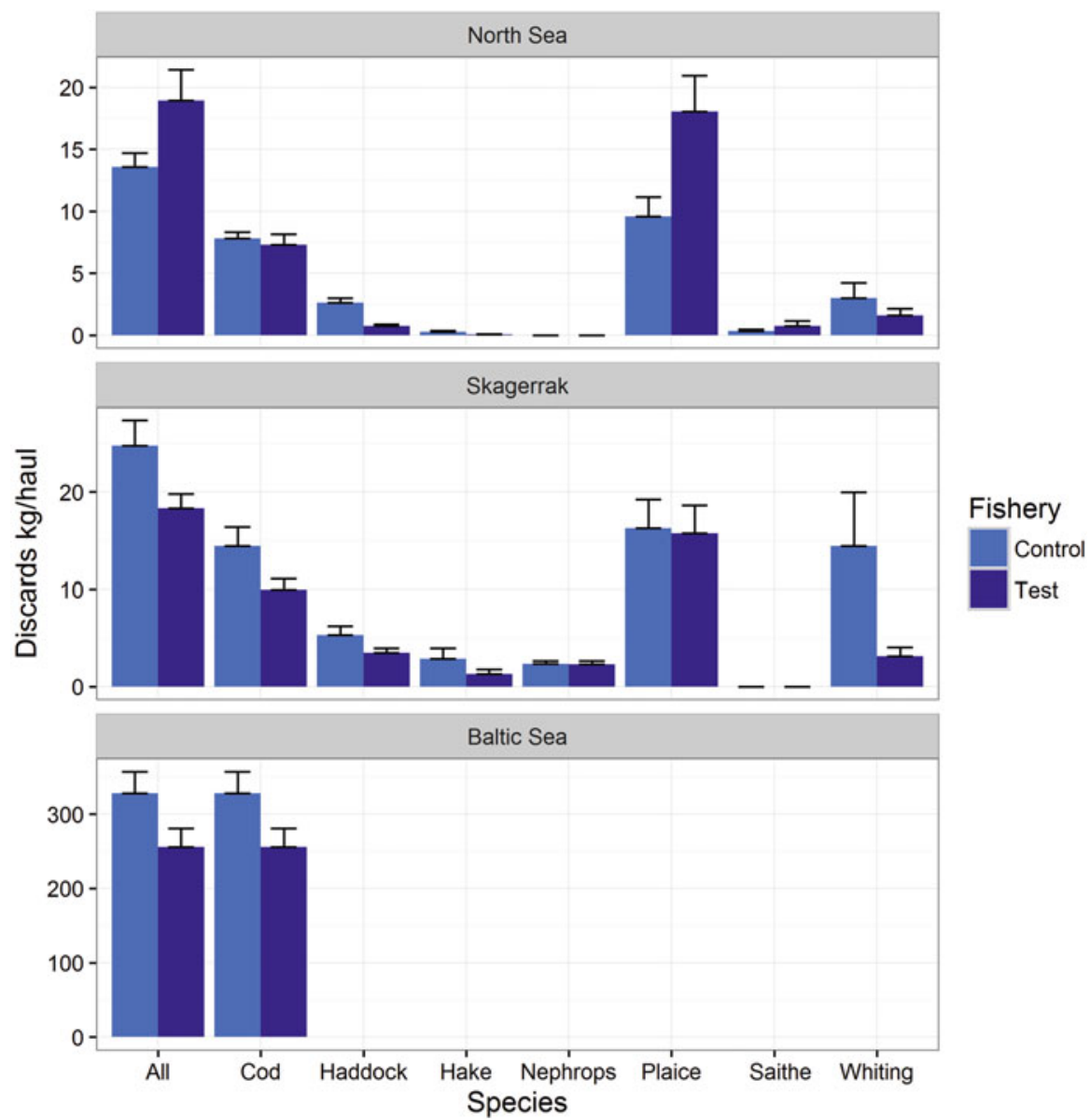

Fig. 13.1 Bar chart showing the average overall discards per haul from each area and the average discards per haul of individual species in each area. Error-bars signify standard error. Note that y-axes differ between areas. (From Mortensen et al. 2017)

\subsubsection{Tactical and Strategic Changes Used in the Challenge Trials}

Tactical and strategic changes to fishing to reduce discards were mainly tested in the Irish and French Challenge trials. In the Irish trials, the whitefish targeting vessel used changes in both the time of day and also in the depths of fishing. The vessel also tried to move between management areas to maximise the time fishing for the month. The main issue for this vessel in the control period was a very early choke on cod and haddock in all management areas. The combination of area and behavioural changes allowed a small change in choke time across all areas from 4 to 9 days. There was some evidence that the skipper was actually trying to avoid discards during the 


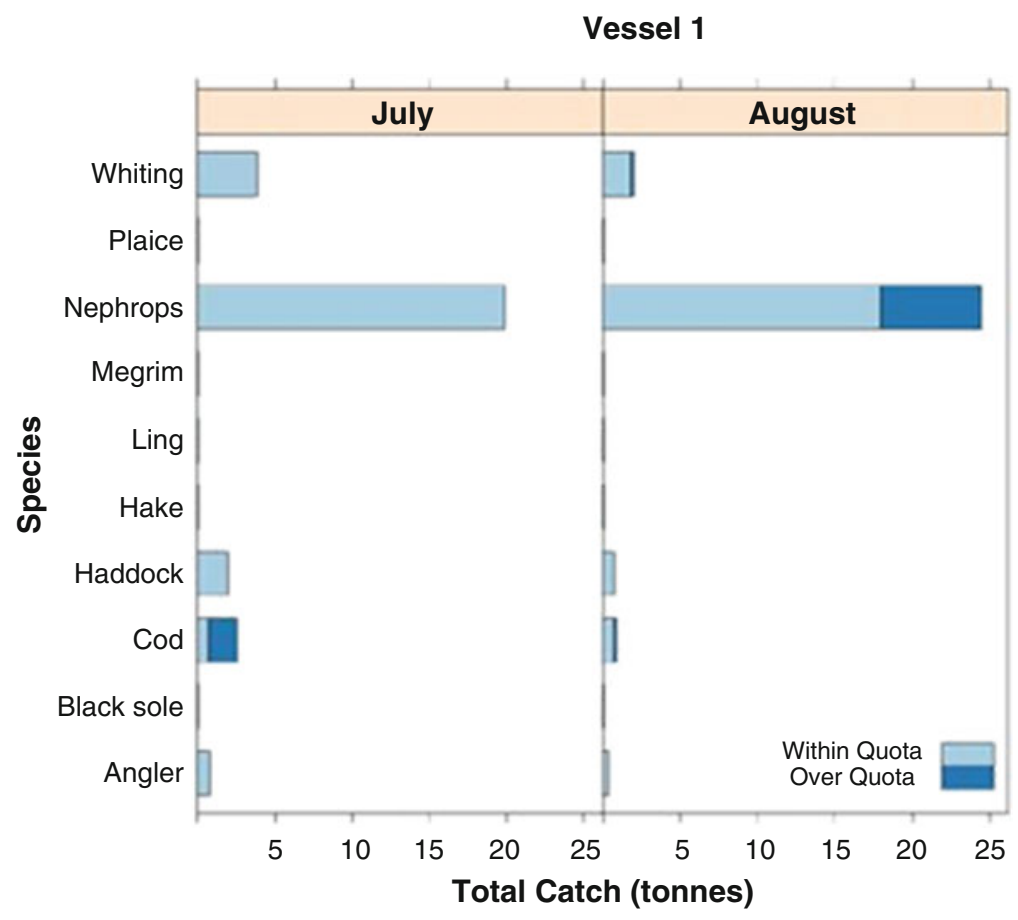

Fig. 13.2 Total catch of quota species for the Nephrops vessel during the 2 months of the trial, with a distinction between within quota landings (light blue) and over quota/< MCRS (over Minimum Conservation Reference Size) landings (dark blue). (From Calderwood et al. 2016)

control periods as well - he had somewhat higher discards in the months prior to the trials than in the control month during the trials. This may have impacted on the outcomes from the changes he made. The Nephrops vessel, while focused on the gear changes outlined above, also used movement between management areas to successfully reduce the choke problem (Fig. 13.3).

The strategic changes made by the French vessels were mainly focused on the potential for avoiding "sensitive" areas based on traditional ecological knowledge, characterised by high catch rates of quota species under MCRS. The outcomes suggested that the large vessel already did this in its normal practice, and that scope to do any more was limited. For the smaller vessels, their main operating area with high discards was within the three mile zone along the Channel coast, where almost $70 \%$ of their catch was usually discarded (Fig. 13.4). Avoiding this area would clearly help with their landing obligation (LO) requirement. The key issue was that, while discards are high in this zone, it is also their main area of operation. These are small, artisanal vessels, and this area is both close to their home ports and also sheltered from bad weather. As a consequence, the skippers were reluctant to avoid this area during the trials. However, it remains a potential valuable tool for discard mitigation under the LO, and ways to encourage the avoidance of this area should be explored. 


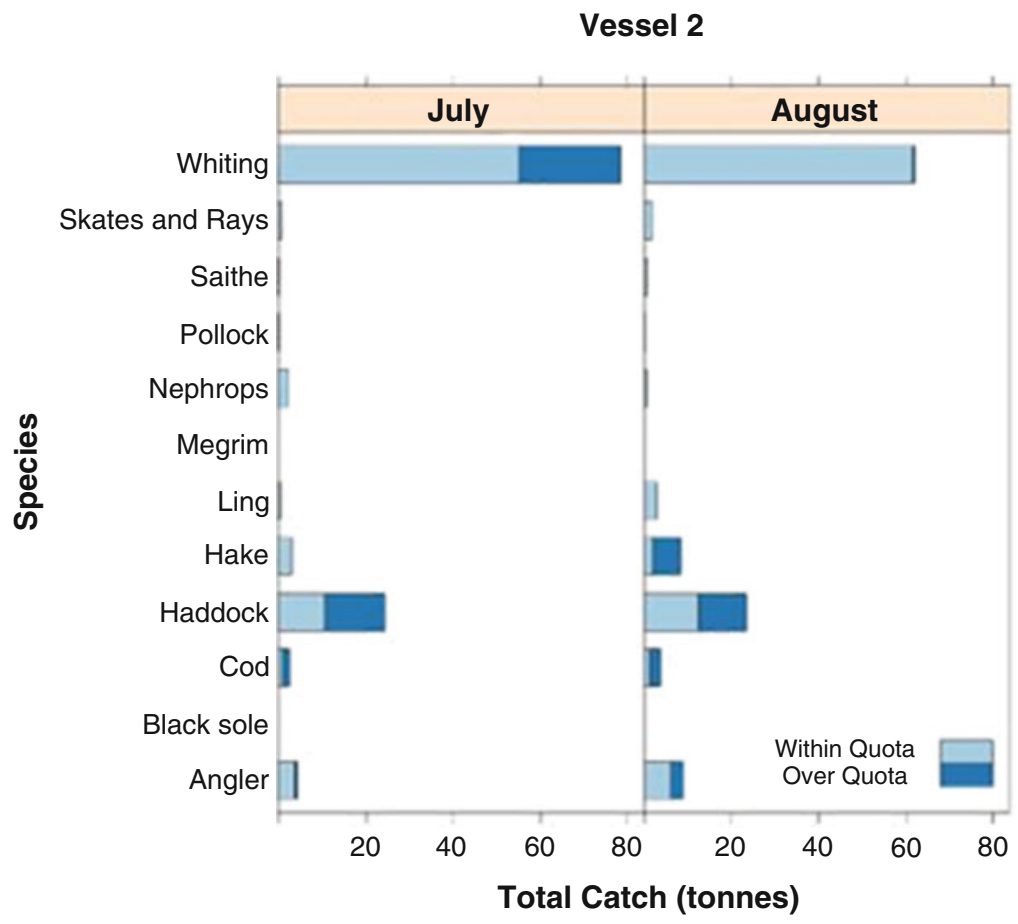

Fig. 13.3 Total catch of quota species for the white fish vessel during the 2 months of the trial, with a distinction between within quota landings (light blue) and over quota/below Minimum Conservation Reference Size (<MCRS) landings (dark blue). The vessel was able to reduce his over quota whiting catch, but could make little change in his over quota cod or haddock catches. (From Calderwood et al. 2016)

\subsubsection{Conclusion}

The use of modified gears to improve selectivity and reduce the scale of discarding showed some promise during the challenge trials. In all three cases, the use of added panels, changes in codend mesh size and configuration, modifications to the extension, and the use of separator panels with twin codends showed some improvements. However, it should be noted that these improvements were often quite small and would probably not solve all the problems fishers would face under a full implementation of the LO. Additionally, these were the fishers' own trials, and could not always be fully substantiated in a scientific context. One positive approach that could be taken, would be to enhance the institutional paths for a "fast-tracking" of such bottom-up initiatives (O’Neill et al., this volume).

The challenge trials showed that there was some scope for the use of both more selective gear and changes in behaviour, both locally, and in moving between management units, to reduce discards, and mitigate the impacts of the LO on fishing viability. Fishers in all the trials did believe that these changes could make some 


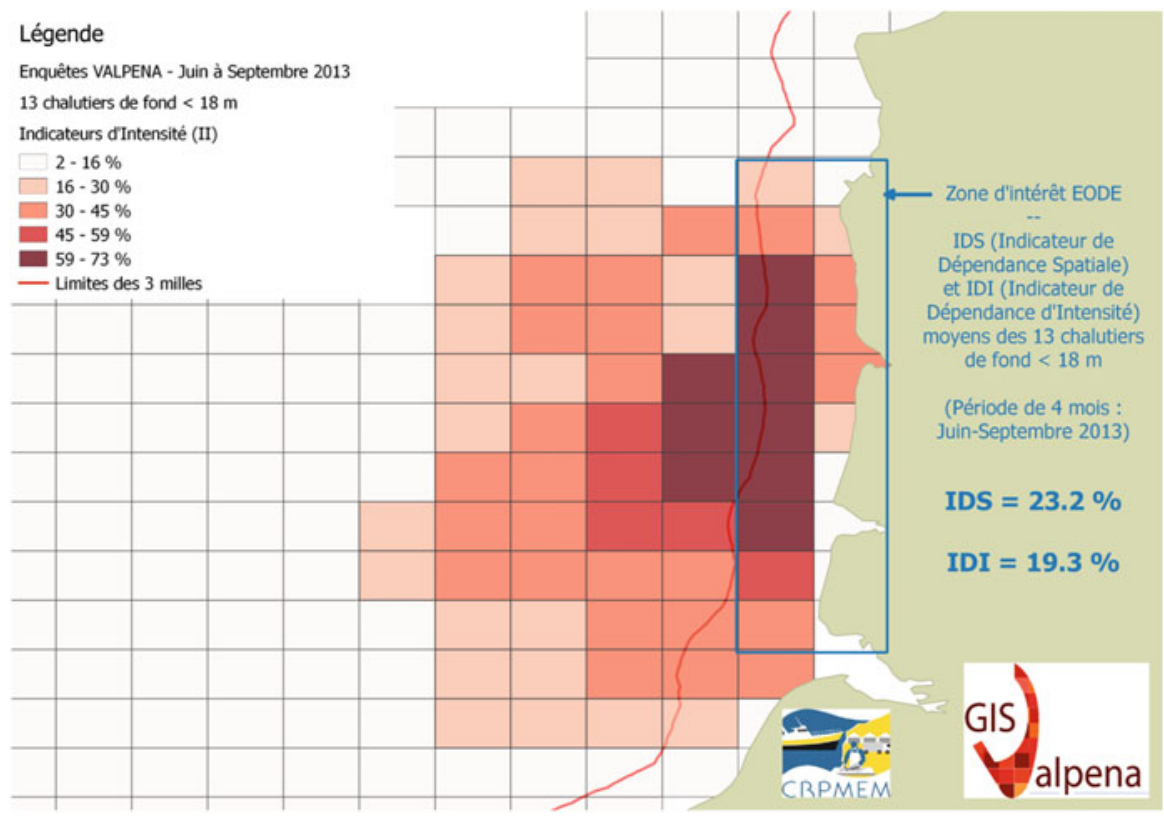

Fig. 13.4 Map showing Intensity Indices (II) of 13 trawlers under 18 meters over the period JuneSeptember 2013. (Source: CRPMEM NPdC-P and Gis Valpena)

difference, even if they did not work as well as expected in the limited context of the challenges. It should be noted though, that even when the trials were able to reduce discarding or the impact of choke species, the improvements were generally quite small. So, while such changes may help fishers comply with the LO by reducing discards, they are still not sufficient to avoid significant impacts on economic viability. Notwithstanding this, we consider it desirable to continue working with fishers on both gear and behavioural based responses to the challenges implicit in the LO. The trials were all successful in terms of the level of collaboration and in some of the outcomes, so such approaches should continue.

\subsection{Where and When to Fish to Avoid Unwanted Catches - How the Scientists Can Help}

Based on the challenge trials and interviews with fishers (Reid 2017), it was clear that tactical changes could help avoid unwanted catches, and we believe that more information would help fishers achieve this. We then looked for ways to provide the detailed knowledge that can come from using scientific data to illustrate the spatial and temporal distributions of the fish, catches and discards.

Fisheries institutions have access to a range of data. These include research vessel surveys showing abundance distributions, observer data showing detailed catch 
(landings plus discards) by commercial vessels, landings and vessel monitoring system (VMS) data showing where and when catches are made, and Fully Documented Fisheries pilot studies showing full details of complete fishing operations. We set out to use this information to develop the potential to assist fishers in making strategic choices to avoid discard. This included fine-scale, real-time mapping of catches and activity data, discards hotspots, juvenile surveys, etc. One aim was to provide Decision Support Tools (DST) to assess the role of "choke" species at the local scale. The role of the scientist here is as an advisor to fishers, about where and when they might fish to reduce choke problems and avoid unwanted catches.

No single approach was possible across all the examples shown below, and indeed was probably not desirable, as each had its own specific issues and context. These arose from a combination of how fish were distributed i.e. in discrete areas, or widely spread, and on the nature of LO requirements, e.g. avoidance of particular species or size classes, and the limitations in fishing imposed by geography and other legislation drivers.

DST can take many forms. At their simplest, these can be maps of where fish are found (from surveys), caught and discarded (from observers). However, more detailed analyses can be used to analyse spatial patterns and their variation, how discards and catches of numbers of species co-occur in space and time, or not. The information can also be represented in an interactive form using web-based apps. But the DST process can also simply be the provision of understanding discarding and its drivers, e.g. quota management rules, or about the interaction of economic profitability with discarding - is it economically better not to discard? We present examples of all these types of Decision Support information. These cover case studies from the North Sea, through North East Atlantic (European western waters) to the Mediterranean Sea. They cover many different metiers and fleets, from single to multi-species, using a wide variety of fishing gears.

\subsubsection{Decision Support Tools Using Survey Data}

Fisheries surveys are carried out across the EU and provide valuable data. The use of survey data in helping fishers to decide where and when to fish is illustrated with an example from the Balearic Islands (in the western Mediterranean Sea). The surveys were used to model the spatial patterns of species abundance for the main commercial species. The results from this were a series of maps of species distributions above and below MCRS, species overlaps, fishing grounds, discard hotspots etc. An example showing the density and persistence of thornback ray Raja clavata is presented in Fig. 13.5. In a second example, the degree of species overlap is presented in Fig. 13.6, illustrating where more than one species is likely to be caught together. Other data products from this study also made use of observer data to supplement the surveys.

In the Azores, habitat suitability models for 10 species of deep-water sharks and rays were developed based on survey data (Fauconnet et al. 2018). Deep-sea sharks, 

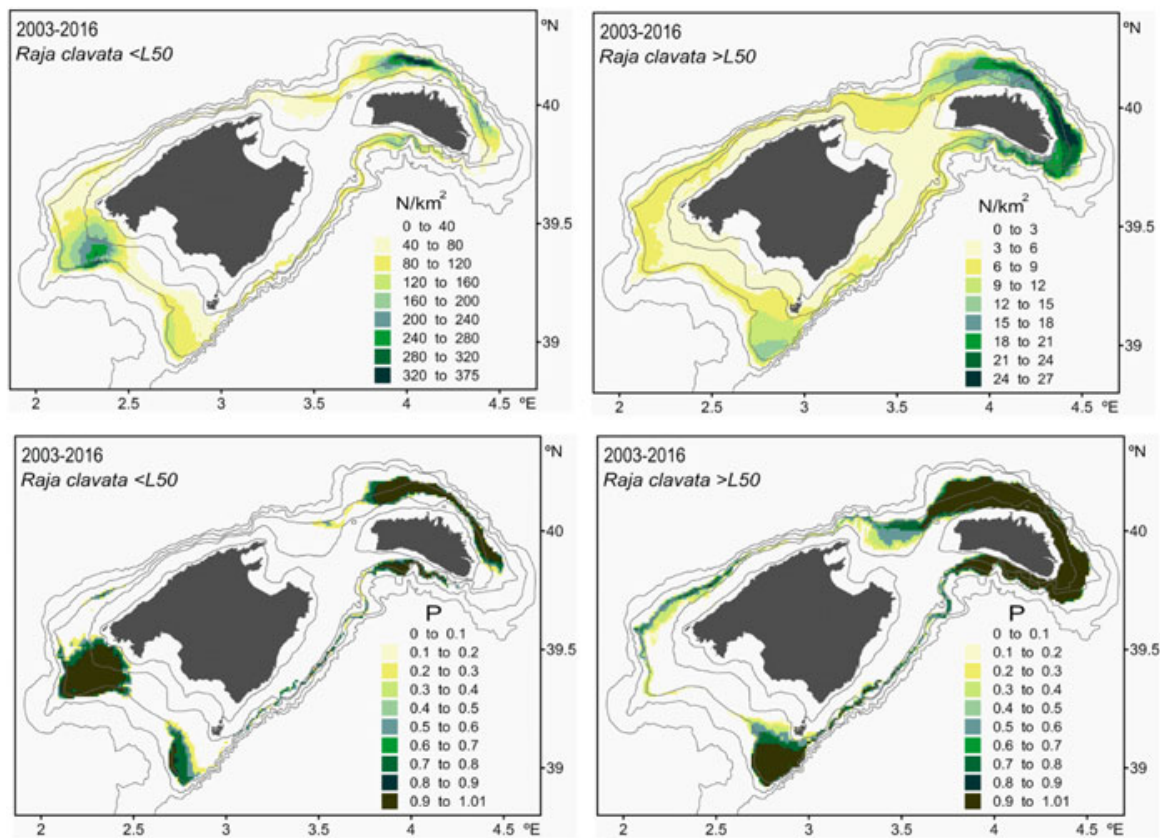

Fig. 13.5 Maps of density (N individuals $/ \mathrm{km}^{2}$; above) and persistence (P, fraction of years; below) of thornback ray individuals from the Balearic Islands under $(<\mathrm{L} 50)$ and over $(\mathrm{L}>50)$ the size at first maturity $(73 \mathrm{~cm})$

even if only occasionally taken as bycatch of the deep-water longline fisheries in the Azores, could rapidly choke the fisheries of this Portuguese outermost region, as many of those species are currently managed under a zero TAC. Maps predicting occurence by species and combined occurence of all species at the range of the whole Azores EEZ were developed using data from demersal bottom longline surveys carried out from 1996 to 2017 (Fauconnet et al. unpublished data), to help fishers identify areas they should avoid to limit the risks of catching those species (Fig. 13.7). Composite maps combining the distribution of the main shark species caught by the bottom longliners, and by the deep-water drifting longliners were also created to better highlight the main areas to be avoided for those two groups of fishers. This information was completed using fine-scale information on deep-water shark spatial and vertical movements derived from acoustic telemetry data from 2 species: kitefin shark (Dalatias licha) (Fig. 13.8) and bluntnose sixgill shark (Hexanchus griseus). Telemetry data helped identify potential essential habitats for those species. The study highlights that areas to avoid fishing and limits in fishing depths at some time of the day could be promising mitigation measures for fishers to implement to avoid some species of deep-water elasmobranchs - but not for all. 


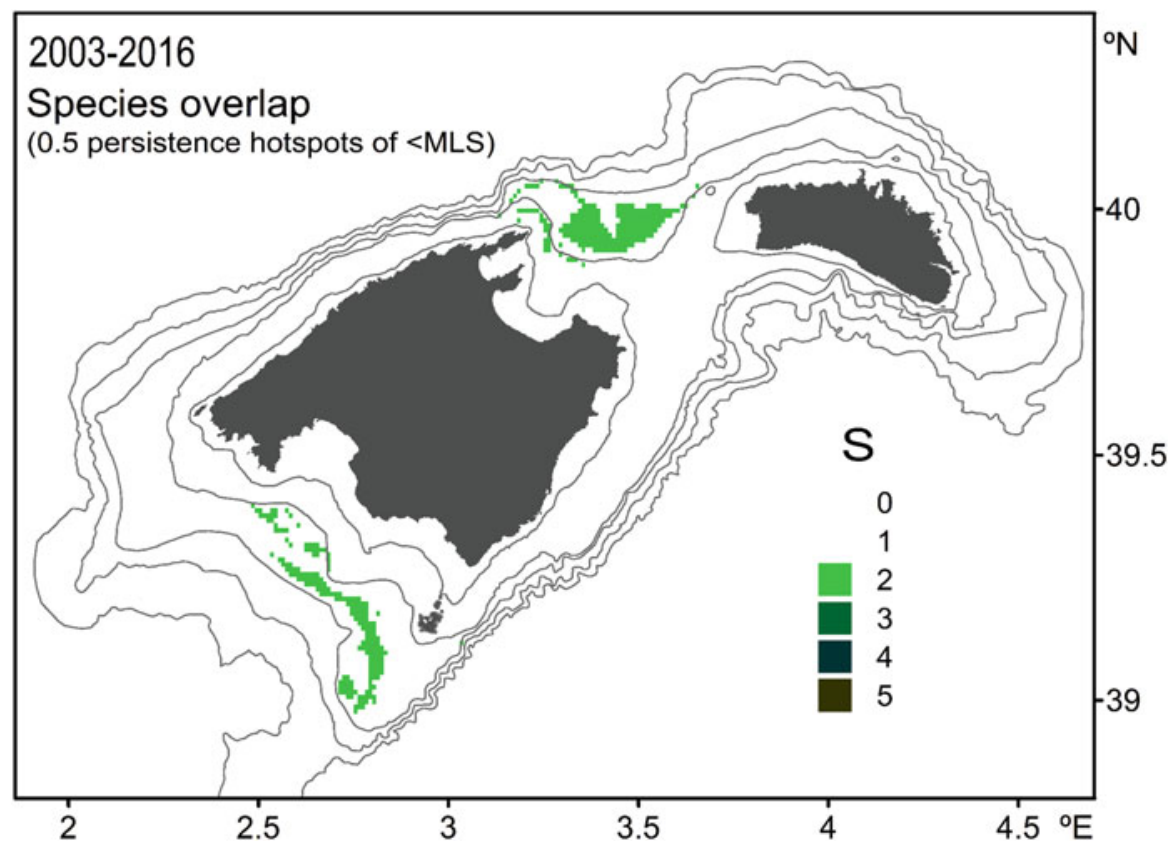

Fig. 13.6 Map of the number of species overlapping $(S)$ in the mixed bottom trawl fishery from the Balearic Islands; S was obtained considering the Minimum Landing Size (MLS) of each species and a persistence level of 0.5

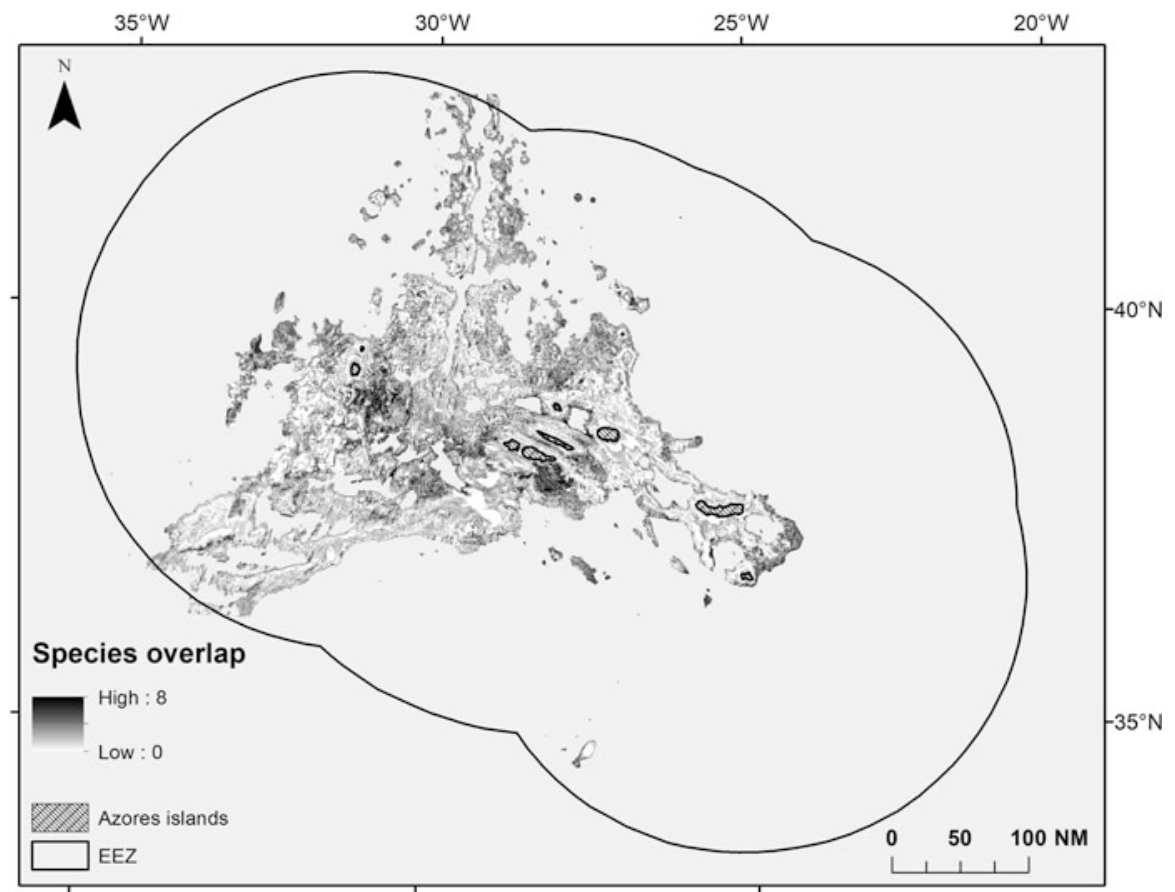

Fig. 13.7 Deep-water elasmobranchs hotspots distribution overlap based on presence/absence distribution of the 10 selected species. Uniform light grey represents areas with no data. (Fauconnet et al. 2018; Fontes et al. 2015) 


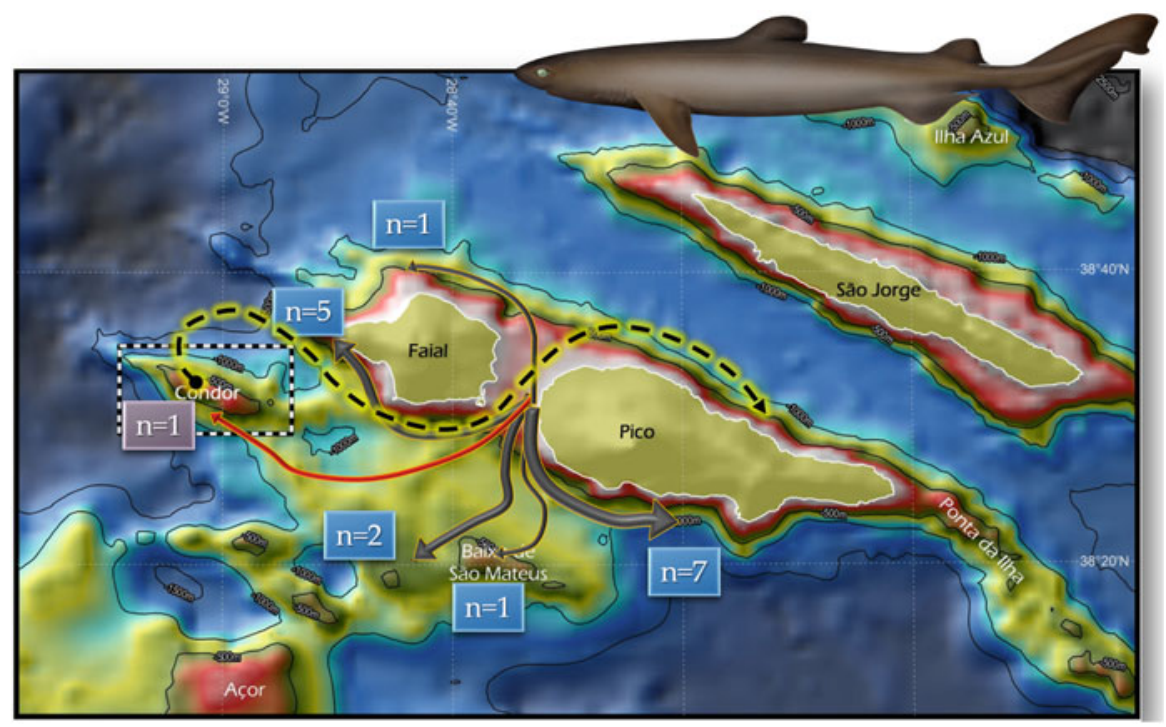

Fig. 13.8 Graphical representation of the movement ranges of individual kitefin sharks tagged with acoustic transmitters at the south of the Faial-Pico channel and monitored using deepwater acoustic receivers in the islands' slopes and neighbouring seamounts; boxes represent the number of sharks undertaking a particular movement. (Fauconnet et al. 2018)

\subsubsection{Decision Support Tools Using Observer Data}

Observer data come from on-board observers on commercial fishing vessels, and, like surveys, similar coverage is carried out across the EU. Their primary task is to record discards, but they also record fish that go to landings. Thus they represent very detailed information on catches, landed and discarded. It is only possible to deploy observers on a small proportion of all fishing trips, but we were able to combine observer data from France, Ireland and the UK for the Celtic Sea to provide a larger dataset to work on, and some of the results are shown here. Two different approaches are presented as examples of what information can be produced.

\subsubsection{Where Are Discards Clustered Together?}

This study is the first multispecies, fine scale, spatial analysis of landings and discards in mixed fisheries across a multinational context. The core aim was to use observer data to identify where commercial fish were landed and discarded and with what other species. Multivariate analysis (Principal Component Analysis PCA and hierarchical clustering) on combined observer data from Ireland and France between 2010 and 2014 grouped cells of space characterized by homogeneous species profiles in terms of discards (or landings). Each cluster was then plotted on a map with a 


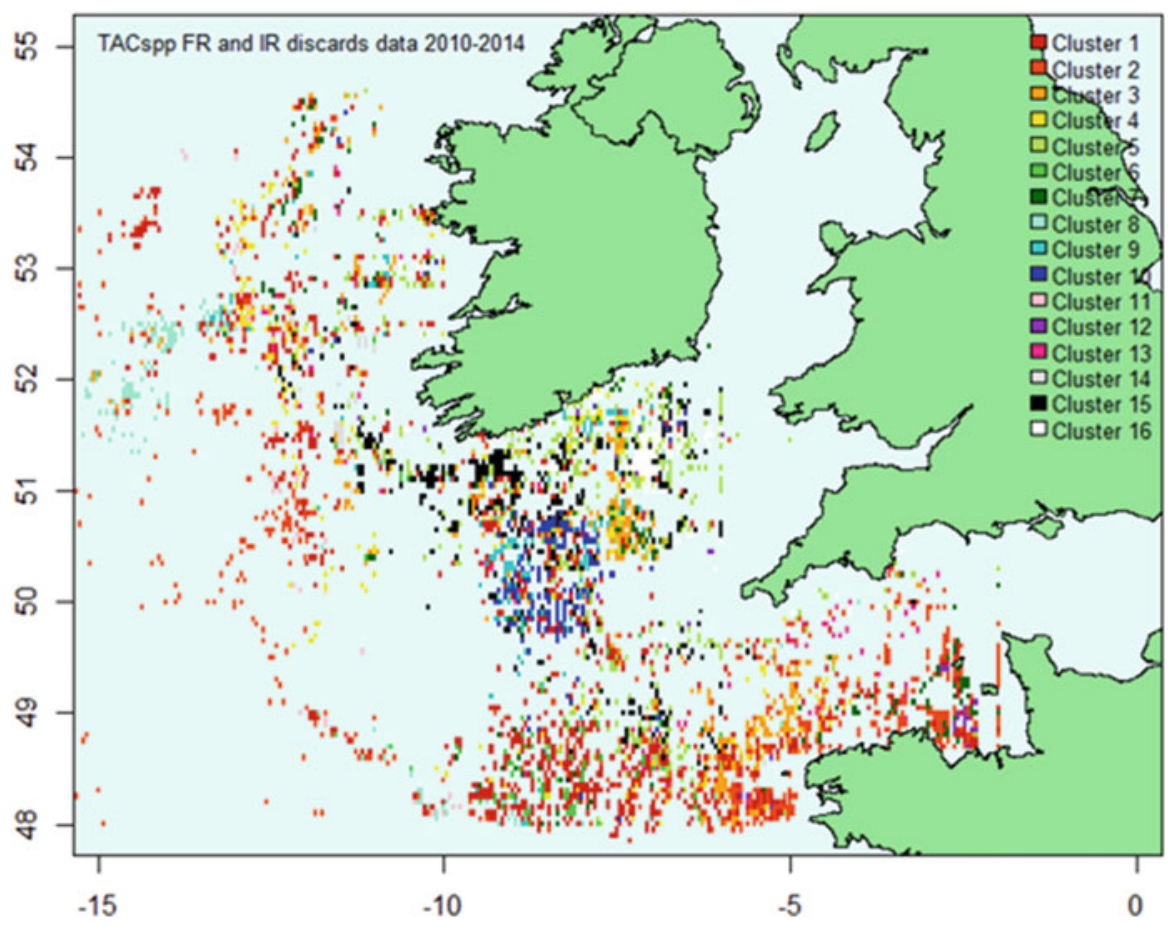

Fig. 13.9 Cluster maps of French and Irish discards. The same colour code was assigned to each $3^{\prime * 3^{\prime}}$ square belonging to the same cluster. This analysis was for TAC species only

colour code. It provides a global overview of discards and landings locations by species in the central region of the Celtic Sea. What was found was a highly structured fishing ground, with some of the clusters only found in a smaller part of the whole Celtic Sea. For instance, in the map shown in Fig. 13.9, there is a notable patch of the dark blue cluster 10 in the middle of the area. This cluster mainly represents observed discards of Norway lobster and spurdog (Squalus acanthias). But the more widely spread red cluster 13, was mainly composed of mackerel (Scomber scombrus) and sprat (Sprattus sprattus). While some discard clusters corresponded well to landings clusters spatially, this was less common than cases where no obvious common pattern was found. This result suggests that in the central Celtic Sea, landings profiles in terms of species may not predict discards species composition.

\subsubsection{Mapping Catch Hot Spots to Avoid Unwanted Catches}

A valuable support tool for fishers would be to have access to maps showing species abundance hotspots - that is, areas where there would be a high probability of catching a given species, above or below MCRS. This was carried out using a 


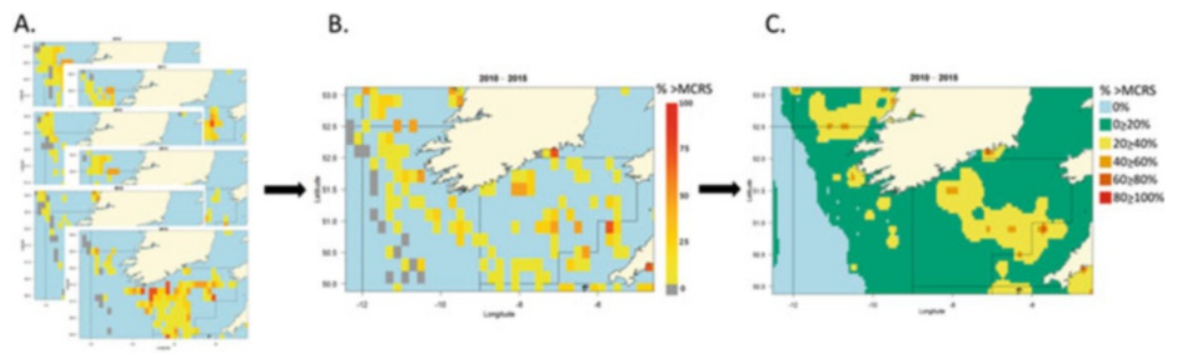

Fig. 13.10 Diagram showing the steps in the map production process. (A. Individual binned maps created for each year; B. Amalgamated map for all years identifying grid cells within consistent binned categories over multiple years; C. Final interpolated map (using inverse distance weighted interpolation)

detailed analysis of observer data from Ireland, France and the UK used as an indicator of the catches taken in the Celtic Sea. The analysis focused on mapping hot spots of CPUE and catch proportion for three key species; cod, haddock and whiting, and over and under MCRS. The analysis can be extended to any species, both commercial and non-commercial. The maps were based on consistent observations of particular catch rates, so only those locations where one would consistently (over 5 years) see high or low levels for these categories were used. The data were then interpolated to provide regional coverage (Fig. 13.10). The maps were then drawn together into a web-based app (discussed below).

\subsubsection{Detailed Haul-by-Haul Mapping Using Electronic Monitoring Data}

Another option to monitor catches is the use of Electronic Monitoring (EM) systems with video on board vessels that can monitor the haul-by-haul catch remotely. Such a system has been trialled in Denmark since 2008 (Bergsson et al. 2017; Ulrich et al. 2015). The analysed footage provides detailed information on discards, covering more trips and hauls compared to observer trips, for vessels carrying the system. An example is shown in Fig. 13.11.

Fine-scale information on landings and discards by haul can be combined with the landing price for the trip to map trade-offs between high-value and high-discard fishing spots, which can potentially complement the fisher's implicit knowledge on the best fishing locations (Plet-Hansen and Ulrich 2018). An example for a single vessel for which such a detailed information is available is presented in Fig. 13.12. 


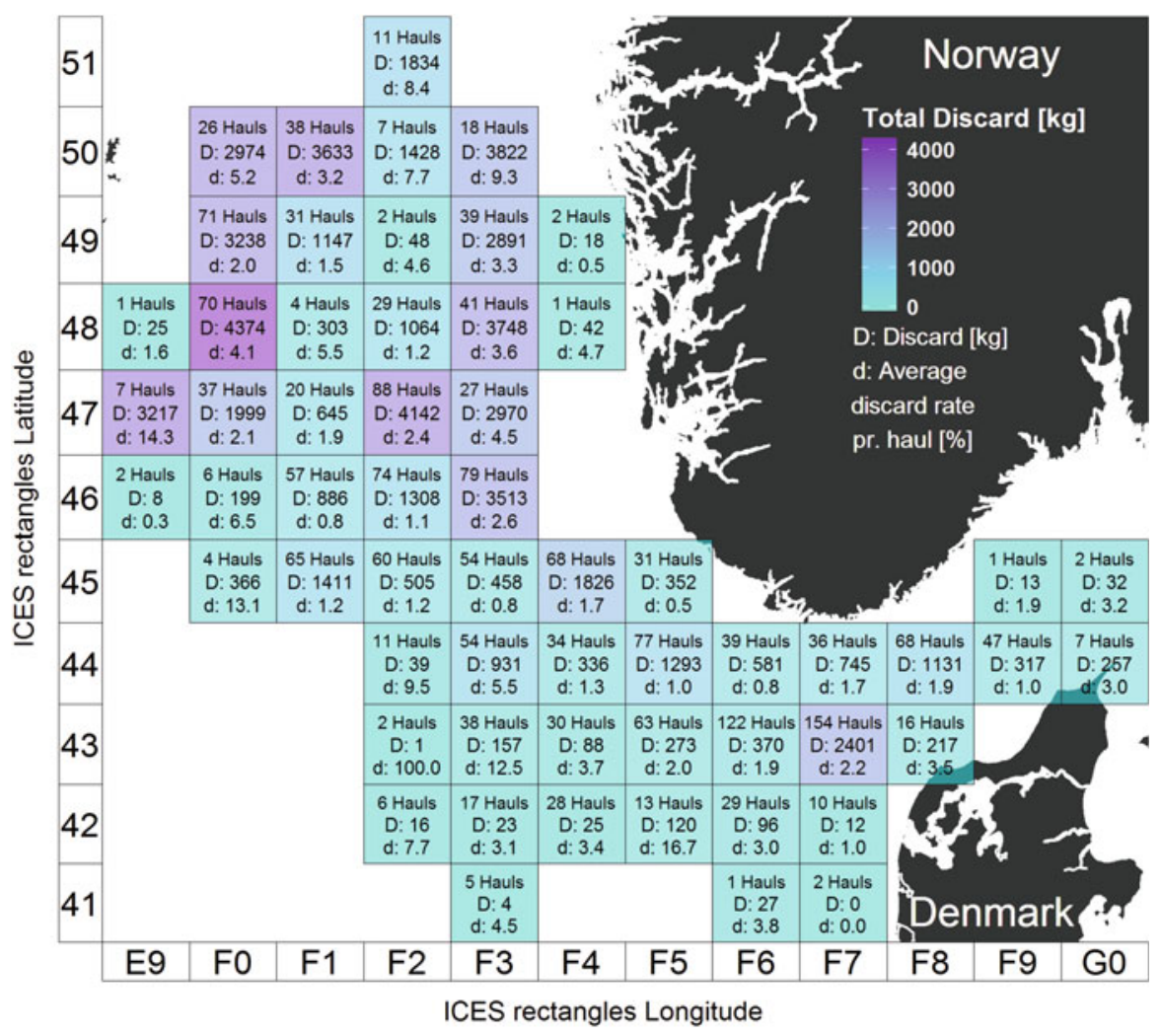

Fig. 13.11 Map of 2016 EM discard data for cod, hake, saithe, whiting and haddock from 12 Danish vessels (sampled hauls with video footage reviewed representing 29\% of all their hauls that year). Cyan areas have low total discards in $\mathrm{kg}$, purple areas have higher total discards. Each grid cell is an ICES rectangle. The x-axis shows the ICES rectangles' longitudinal ID, the $y$-axis shows the ICES rectangles' latitudinal ID. The number of sampled hauls conducted in each ICES rectangle by the 12 vessels is written together with the discard in $\mathrm{kg}(\mathrm{D})$, and the average discard rate (Discards/Catch) for the 5 species per haul (in \%). (From Bergsson et al. 2017)

\subsubsection{Combining Surveys and Commercial Catch Data to Provide Year-Round Abundance Distributions}

Data from scientific surveys are not available for all times of the year but provide consistent yearly and spatially resolved abundance indices. On-board commercial data cover the whole year, but generally provide a biased perception of stock abundance. The combination of scientific and commercial catches per unit of effort (CPUEs), standardized using statistical methods (in this example a delta-generalized linear model), allows the description of the spatial and temporal (monthly) dynamics of fish distributions in the Eastern English Channel (Bourdaud et al. 2017). Using the scientific survey as a baseline, the degree of reliability of commercial CPUEs was assessed with survey-based distributions using the local overlap between 


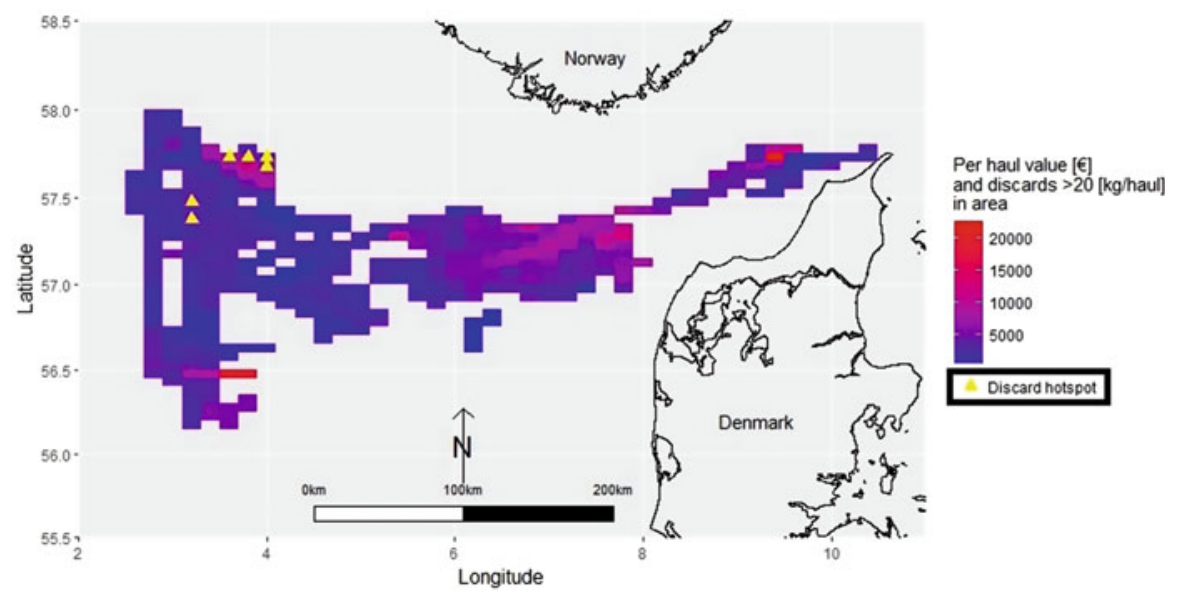

Fig. 13.12 Gridded map of the landing value per haul for a single Danish trawler. The red colour represents the greatest value per haul. The yellow triangles represent the areas of high discard volumes. The discard hotspot areas often coincide with high value hauls but importantly, there are also other high value areas without such high discard levels. (From Plet-Hansen and Ulrich 2018)

distributions. The broader spatio-temporal estimated distribution of the species agreed with qualitative information from the literature, especially for cuttlefish, and this is illustrated in Fig. 13.13. Fine scale consistency (using cells of $0.3^{\circ} * 0.3^{\circ}$ ) between survey and commercial data was significant for half of the 19 tested species (e.g. whiting, cod). For the other species (e.g. plaice, thornback ray), the results were inconclusive. The approach allowed a more representative mapping of the abundance distribution across the year, that can then be used in both targeting, and avoidance in the context of the LO.

\subsection{Web-Based Apps to Help Fishers Plan Where and When to Fish to Avoid Unwanted Catches}

In many of the analyses in this chapter, the scientists concerned have been able to produce information, usually in map form, that has the potential to help fishers target their activity to avoid unwanted catches. To make this practically useful, and useable, scientists have started developing a range of web-based apps both to present the information, but critically, to allow the fishers to work with it in their own way. In three of the examples given in the above descriptions, such apps have been developed and are, or will be, refined with fishers to make them as useful as possible.

One example developed in the Balearic Islands is presented in Fig. 13.14. The app allows fishers to choose the species and fishing ground of interest. They can then see 

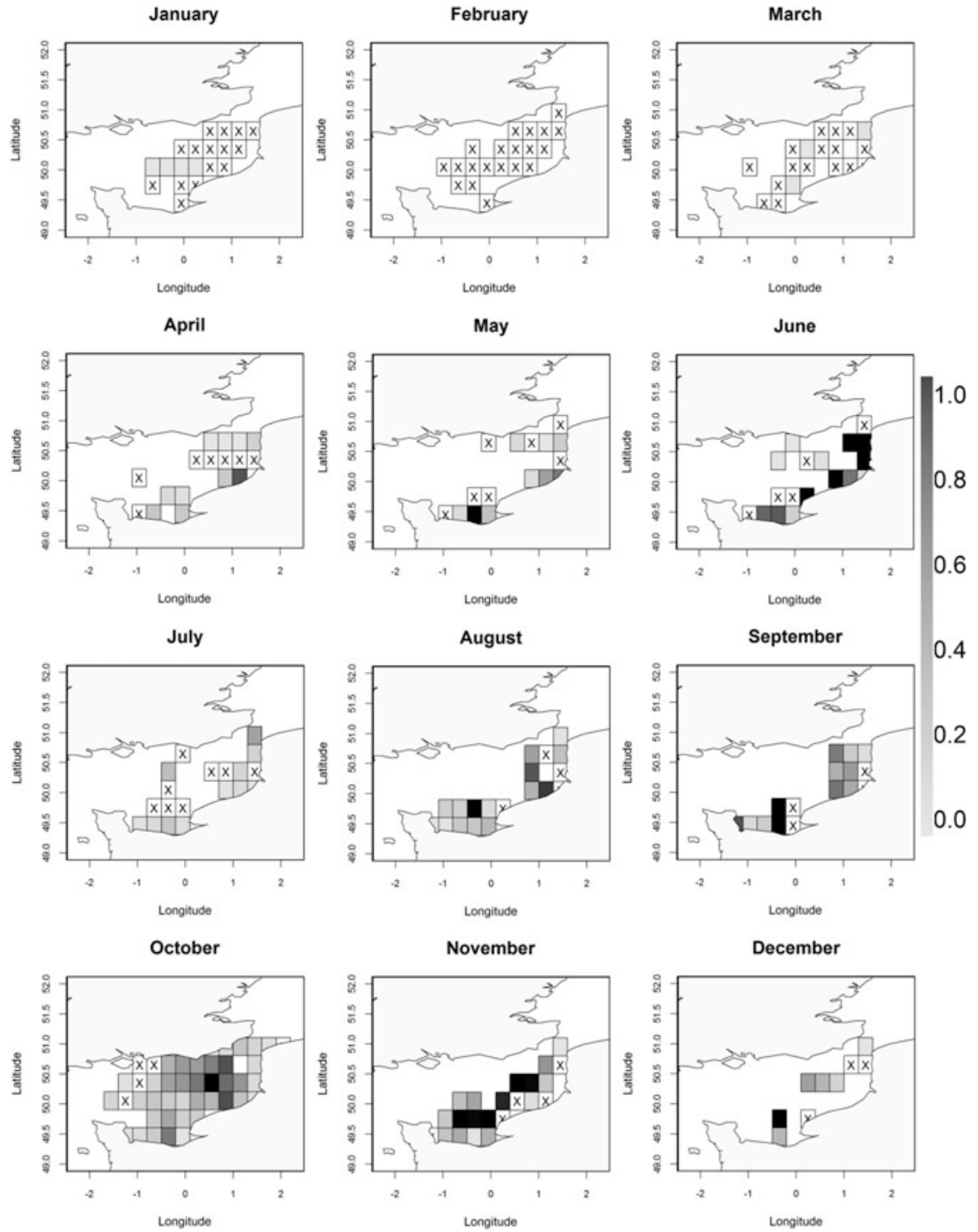

Fig. 13.13 Monthly spatial abundance distribution estimated from on-board commercial observations (OBSMER program in France) and scientific surveys (CGFS, Channel Ground Fish Survey) for cuttlefish. The crosses in the white squares $(\mathrm{X})$ represent areas where no cuttlefish was ever fished during a month. (Figure from Bourdaud et al. 2017)

observer or survey data, as well as discard information, length and maturity data, and other information on the species and the fisheries.

A second example, developed for the Celtic Sea fisheries, is presented in Fig. 13.15, where the fishers can choose the species (or size class) of interest, and 


\section{Balearic Islands Bottom Trawl Fleet (Western Mediterranean)}
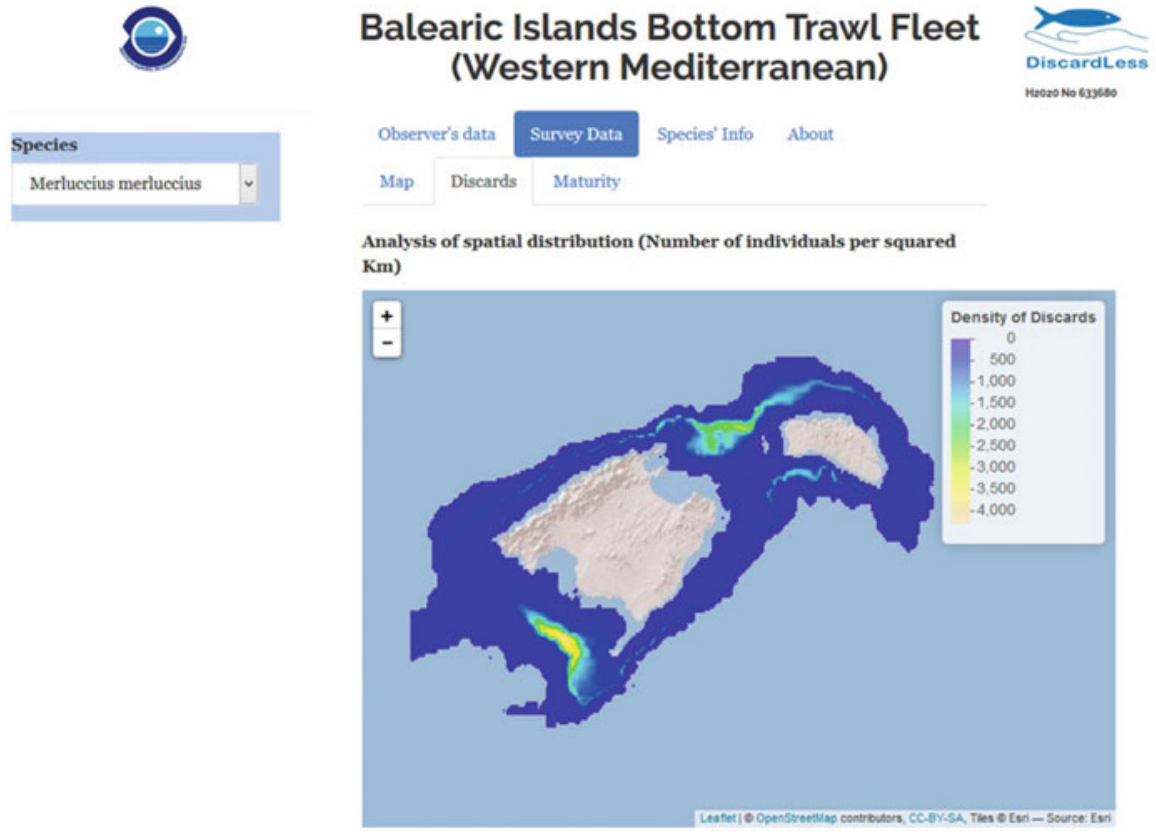

Fig. 13.14 Snapshot of the Shiny App produced as a decision support tool to assist fishers in the Balearic Islands to make choices of fishing location to avoid discards. Density map (number of individuals per $\mathrm{km} 2$ ) of hake discards (individuals under the MLS $=20 \mathrm{~cm}$ ) is shown

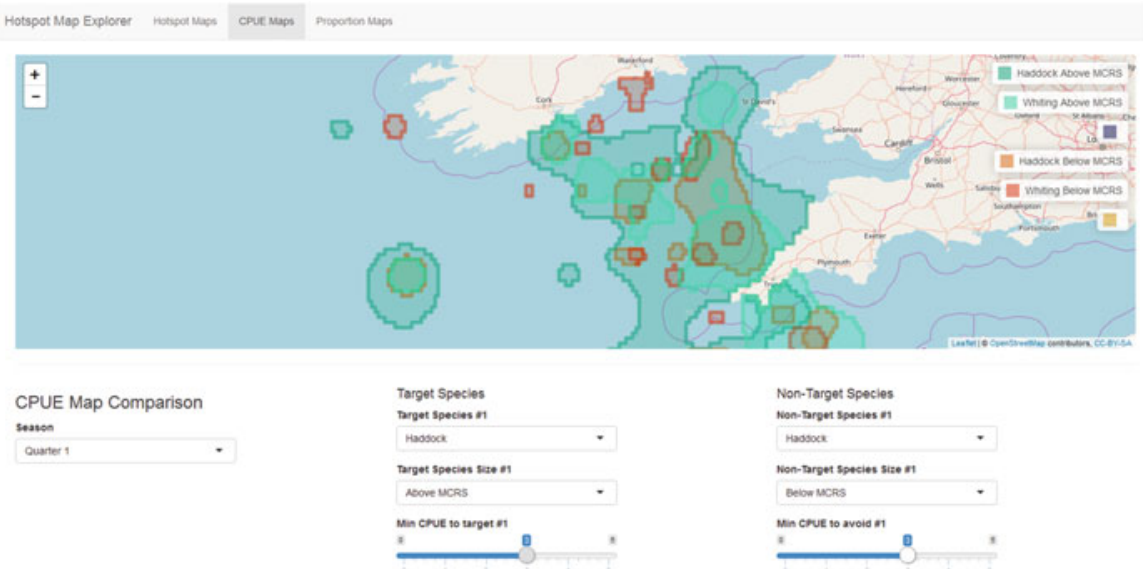

Fig. 13.15 A screenshot of the Shiny App developed to allow stakeholders to select the size, species and quantity of fish they would like to target and/or avoid during different seasons. The resultant map displays layers allowing fishers to balance trade-offs of target and non-target to optimise catch composition. 


\section{Using the tool to identify potential avoidance areas (quartely scale)}

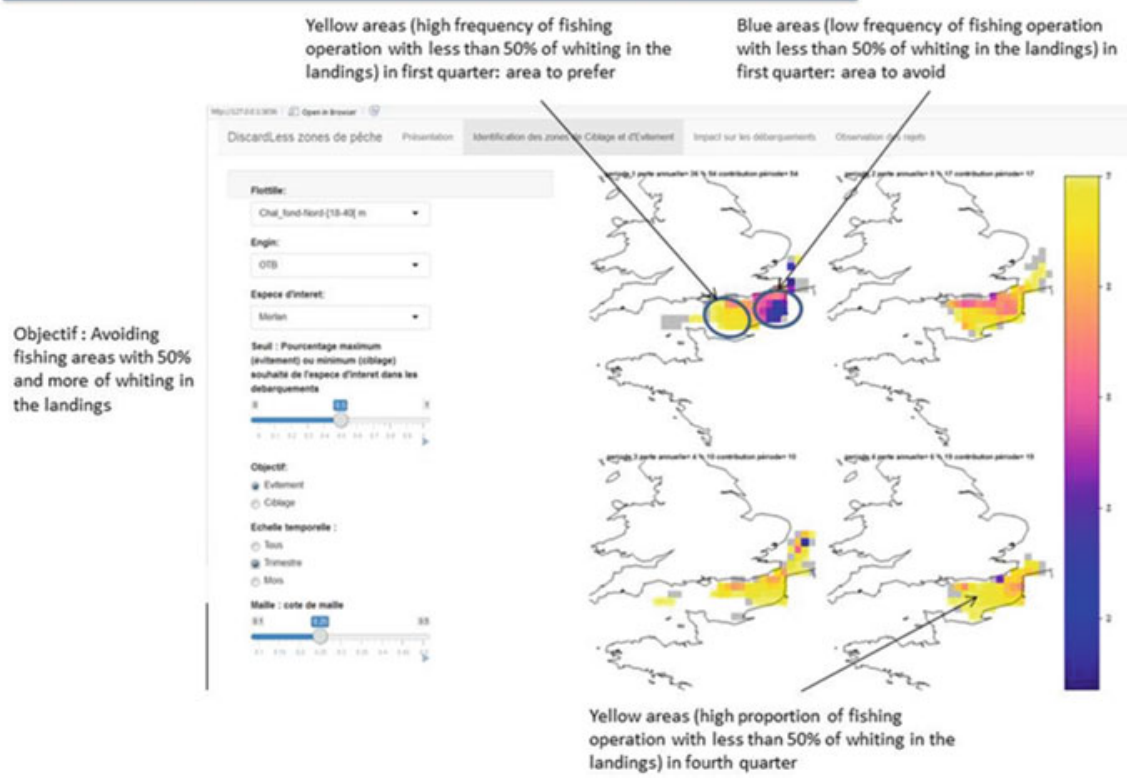

Fig. 13.16 An example of the web-based app for the English Channel showing a variety of ways to present information to avoid discards

then map CPUE or catch proportion at the selected level of intensity. They can also map a number of species or sizes together on one map, and change the levels, to help choose the best places to avoid or to find particular species or sizes. The app represents a DST for fishers, and is still under development, but it is planned to incorporate additional species as well as discarding hotspots. The app is a prototype and will be developed working with individual fishers to best fit it to their needs.

The final example is for the fishery in the Eastern English Channel discussed earlier. Again, the app offers the fisher a variety of choices for presentation (Fig. 13.16). They can choose the species, gear and fleet, and look at landings, discards or survey data. As in the Celtic Sea example, fishers can define a maximum or minimum proportion of a given species in the landings that he is willing to accept depending on the objective i.e. avoiding or targeting the species. The time scale over which the maps are presented can also be controlled, either for a year, quarter or month.

\subsection{Conclusions}

The original idea we stated in the title was "The best way to reduce discards is by not catching them!" The work presented in this chapter shows some of the ways that this could be achieved. 
Gear based changes in selectivity remain the most common, default, way to do this, and we present here some of the broad range of such approaches available. Many of these have been developed by gear technologists, but many also by working fishers or netmakers. In many of our studies, we found that fishers remain innovative and willing to explore the use of different gears to reduce unwanted catches.

Behavioural changes by fishers, i.e. tactical changes in where and when to fish, are a second route to avoiding unwanted catches that have attracted less attention than gear-based approaches. In the challenge trials described here, fishers attempted both gear and behavioural changes in their fishing practices. In some cases, these changes reduced unwanted catches but not in all. One of the reasons for this advanced by several fishers involved in the work was that they lacked the information needed to help them choose where and when to fish to minimise the unwanted component.

It is beyond doubt that fishers know their own fishing activity far better than any scientists could. They are, after all, observing it on a daily basis over many years. But, equally, scientists have information that fills in the wider picture on distributions and abundances of fish, both wanted and unwanted. Taken together, fishers' and scientists" "knowhow" can give the working fisher the best chance to reduce, or possibly eliminate, unwanted catches. We have shown here how surveys, observers' information, landings data, etc. can provide useful information on where the fishers are likely to encounter a given species or size class of that species, as well as those fish commonly encountered together. It needs to be emphasised that this information should be seen as providing a probability of encounter or not, rather than a certainty. The take-home message from this is that there is more chance of approaching the objectives of the landing obligation by combining fishers' and scientists' knowledge than by working apart.

Another key message is that we can identify several different approaches that could help reduce discarding, but they all tend to be specific to local conditions. It should be possible to export the approaches to other fisheries, but only in broad terms. Essentially, the causes of discarding are common, but the solutions tend to be local and specific.

Acknowledgments This work has received funding from the Horizon 2020 Programme under grant agreement DiscardLess number 633680. This support is gratefully acknowledged.

\section{References}

Anon. (2011). Atlas of demersal discarding, scientific observations and potential solutions. Marine Institute, Bord Iascaigh Mhara, September 2011. ISBN:978-1-902895-50-5. 82 pp.

Balazuc, A., Goffier, E., Soulet, E., Rochet, M.J., Leleu, K. (2016). EODE - Expérimentation de l'Obligation de DEbarquement à bord de chalutiers de fond artisans de Manche Est et mer du Nord, et essais de valorisation des captures non désirées sous quotas communautaires, Comité Regional de Pêches Maritimes et des Élevages Marins de la Réunion. $136+53$ pp. 
Bergsson, H., Plet-Hansen, K.S., Jessen, L.N., Jensen, P., Bahlke, S.Ø. (2017). Final report on development and usage of REM systems along with electronic data transfer as a measure to monitor compliance with the Landing Obligation - 2016. Danish AgriFish Agency, Ministry of Food, Agriculture and Fisheries. https://doi.org/10.13140/RG.2.2.23628.00645. 61 pp.

Bourdaud, P., Travers-Trolet, M., Vermard, Y., Cormon, X., Marchal, P., et al. (2017). Inferring the annual, seasonal, and spatial distributions of marine species from complementary research and commercial vessels' catch rates. ICES Journal of Marine Science, 74(9), 2415-2426.

Calderwood, J., Cosgrove, R., Moore, S.-J., Hehir, I., Curtin, R., Reid, D.G., et al. (2016). Assessment of the impacts of the Landing Obligation on Irish Vessels, BIM Technical Report. http://www.bim.ie/media/bim/content/publications/Lo,report,2016_final.pdf. 22 pp.

Condie, H.M., Grant, A., Catchpole, T.L. (2014). Incentivising selective fishing under a policy to ban discards; lessons from European and global fisheries. Marine Policy, 45(0), 287-292.

Dunn, D.C., Boustany, A.M., Halpin, P.N. (2011). Spatio-temporal management of fisheries to reduce by-catch and increase fishing selectivity. Fish and Fisheries, 12(1), 110-119.

Eliasen, S.Q., Papadopoulou, K.N., Vassilopoulou, V., Catchpole, T.L. (2014). Socio-economic and institutional incentives influencing fishers' behaviour in relation to fishing practices and discard. ICES Journal of Marine Science, 71(5), 1298-1307.

Fauconnet, L., Das, D., González, J.M., Catarino, D., Giacomello, E., Fontes, J., et al. (2018). Can deep-water sharks be avoided? Spatial mitigation measures in the deep-sea longline fisheries in the Azores. In D. Reid and L. Fauconnet (Eds.), Decision support tool for fishers incorporating information from tasks 4.1, 4.2 and information on unwanted catches derived from scientific data. DiscardLess deliverable D4.3.

Fontes, J., Rosa, A., Graça, G., Giacomelo, E., Cardenal, R., Afonso, P., et al. (2015). Can Deep Sea Sharks respond to short term protection? Looking into the deep (2015). European Elasmobranch Association meeting 2015, Peniche, Portugal.

Fraser, H.M., Greenstreet, S.P.R., Fryer, R.J., Piet, G.J. (2008). Mapping spatial variation in demersal fish species diversity and composition in the North Sea: accounting for species- and size-related catchability in survey trawls. ICES Journal of Marine Science, 65(4), 531-538.

Gerritsen, H., \& Lordan, C. (2011). Integrating vessel monitoring systems (VMS) data with daily catch data from logbooks to explore the spatial distribution of catch and effort at high resolution. ICES Journal of Marine Science, 68(1), 245-252.

Hilborn, R. (2007). Managing fisheries is managing people: what has been learned? Fish and Fisheries, 8(4), 285-296

Little, A.S., Needle, C.L., Hilborn, R., Holland, D.S., Marshall, C.T. (2015). Real-time spatial management approaches to reduce bycatch and discards: experiences from Europe and the United States. Fish and Fisheries, 16(4), 576-602.

Mortensen, L.O., Ulrich, C., Eliasen, S., Olesen, H.J. (2017). Reducing discards without reducing profit: free gear choice in a Danish result-based management trial. ICES Journal of Marine Science, 74(5), 1469-1479.

Nash, R.D.M., Wright, P.J., Matejusova, I., Dimitrov, S.P., O’Sullivan, M., Augley, J. (2012). Spawning location of Norway pout (Trisopterus esmarkii Nilsson) in the North Sea. ICES Journal of Marine Science, 69(8), 1338-1346.

O’Neill, F.G., Feekings, J., Fryer, R.J., Fauconnet, L., Afonso, P. (this volume). Discard avoidance by improving fishing gear selectivity: Helping the fishing industry help itself. In S.S. Uhlmann, C. Ulrich, S.J. Kennelly (Eds.), The European Landing Obligation - Reducing discards in complex, multi-species and multi-jurisdictional fisheries. Cham: Springer.

Pascoe, S., Innes, J., Holland, D., Fina, M., Thébaud, O., Townsend, R., et al. (2010). Use of incentive-based management systems to limit bycatch and discarding. International Review of Environmental and Resource Economics, 4(2), 123-161

Plet-Hansen, K.S., Eliasen, S.Q., Mortensen, L.O., Bergsson, H., Olesen, H.J., Ulrich, C. (2017). Remote electronic monitoring and the landing obligation - some insights into fishers' and fishery inspectors' opinions. Marine Policy, 76, 98-106. 
Plet-Hansen, K.S., Ulrich, C. (2018). Trade-off between value of landings and discard impact. Presentation at IIFET 2018, Seattle, United States.

Reid, D. (2017). Initial avoidance manuals by case study including tactical, strategic and gear based approaches agreed by scientists and fishers. DiscardLess Deliverable D4.1. http://www. discardless.eu/deliverables/entry/initial-avoidance-manuals-by-case-study. $40 \mathrm{pp}$. Accessed 30 Aug 2018.

Reid, D., \& Fauconnet, L. (2018). Decision support tool for fishers incorporating information from tasks 4.1, 4.2 and information on unwanted catches derived from scientific data. DiscardLess Deliverable D4.3.

Rijnsdorp, A.D., van Overzee, H.M.J., Poos, J.J. (2012). Ecological and economic trade-offs in the management of mixed fisheries: a case study of spawning closures in flatfish fisheries. Marine Ecology Progress Series, 447, 179-194.

Rochet, M.-J., Catchpole, T., Cadrin, S. (2014). Bycatch and discards: from improved knowledge to mitigation programmes. ICES Journal of Marine Science, 71(5), 1216-1218.

Shephard, S., Gerritsen, H.D., Kaiser, M.J., Truszkowska, H.S., Reid, D.G. (2011). Fishing and environment drive spatial heterogeneity in Celtic Sea fish community size structure. ICES Journal of Marine Science, 68(10), 2106-2113.

Ulrich, C., Olesen, H.J., Bergsson, H., Egekvist, J., Håkansson, K.B., Dalskov, J., et al. (2015). Discarding of cod in the Danish Fully Documented Fisheries trials. ICES Journal of Marine Science, 72(6), 1848-1860.

Viana, M., Graham, N., Wilson, J.G., Jackson, A.L. (2011). Fishery discards in the Irish Sea exhibit temporal oscillations and trends reflecting underlying processes at an annual scale. ICES Journal of Marine Science, 68(1), 221-227.

Zimmermann, C., Kraak, S., Krumme, U., Santos, J., Stotera, S., Nordheim, L. (2015). Research for PECH Committee - Options of handling choke species in the view of the EU landing obligation - the Baltic plaice example. European Parliament. 100 pp. https://doi.org/10.2861/808965.

Open Access This chapter is licensed under the terms of the Creative Commons Attribution 4.0 International License (http://creativecommons.org/licenses/by/4.0/), which permits use, sharing, adaptation, distribution and reproduction in any medium or format, as long as you give appropriate credit to the original author(s) and the source, provide a link to the Creative Commons license and indicate if changes were made.

The images or other third party material in this chapter are included in the chapter's Creative Commons license, unless indicated otherwise in a credit line to the material. If material is not included in the chapter's Creative Commons license and your intended use is not permitted by statutory regulation or exceeds the permitted use, you will need to obtain permission directly from the copyright holder.

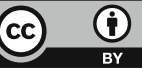

